\section{New visualised anchor for frameless IUD is helpful for checking correct insertion}

Readers of this journal will wish to be aware of an important improvement in the anchoring technology of the frameless copper intrauterine device (IUD), GyneFix $^{\circledR}$ (Contrel Research, Ghent, Belgium). Long-term experience with this IUD is reviewed in a recent publication. ${ }^{1}$ As it has no supporting frame, anchoring of the IUD in the uterine wall is essential. During the learning period, or if the provider is unsure if anchoring was correctly achieved, it is recommended that the correct position of the IUD in the uterine cavity should be
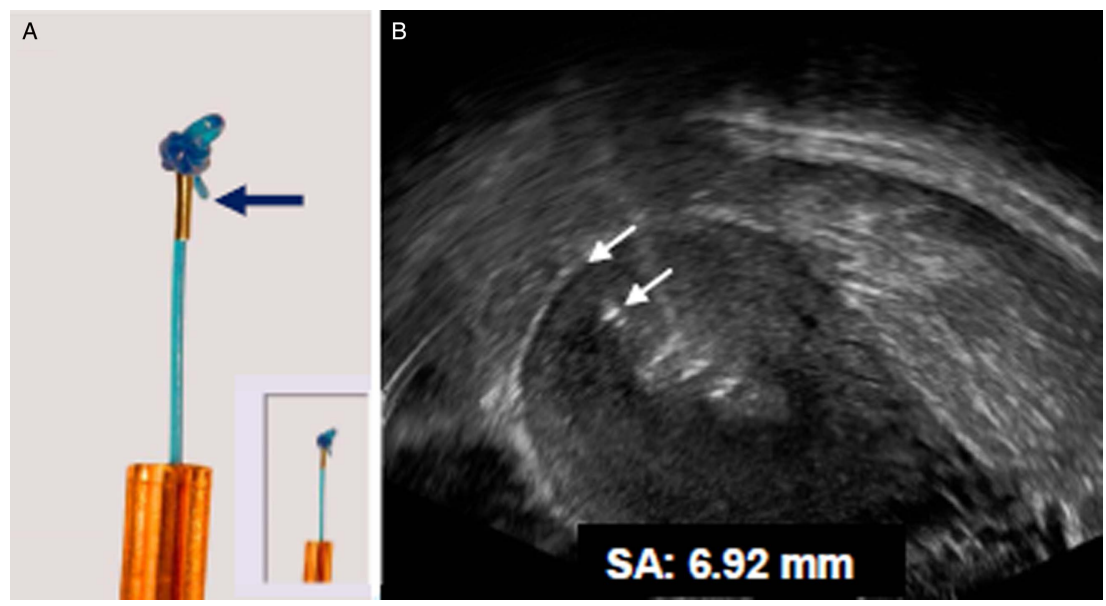

Figure 1 (A) A tiny stainless steel element, $2 \mathrm{~mm}$ long and $0.5 \mathrm{~mm}$ wide, is added on the anchoring thread immediately below the anchoring knot (magnification $\times 2.5$ ). Inset: actual size. (B) On ultrasound, the metal part of the anchor is clearly visible and its distance from the serosa (SA; white arrows) can be measured easily in virtually all cases. as assessed by ultrasound examination at insertion and at follow-up.

Three hundred and nine women (194 nulliparous and 115 parous) requesting GyneFix for contraception participated in this evaluation at five centres in Europe. All insertions were done in consecutive patients in each centre. Following insertion, the stainless steel element was identified on ultrasound and its position in relation to the serosa of the uterus was measured (SA-distance). In 306 of the women the SA-distance could be measured. Two hundred and eighty-one of the 309 women were followed up 12 months after insertion and the SA measurement was repeated. The remaining 28 women were not followed up at the study centres as they had come from abroad for insertion only. The SA-distance was again measured in 77 women between 1 year confirmed. This can easily be achieved using ultrasound, by measuring the distance between the uppermost copper cylinder/sleeve and the uterine serosa (SS-distance). However, the 'anchor' itself (a knot at the upper end of the polypropylene thread) is difficult to visualise although this may be necessary in some cases. The new 'visualised anchor', a stainless steel element attached to the thread immediately below the knot, was developed 3 years ago to help the provider to check its correct position. Currently available GyneFix devices have the visualised anchor and the packaging is marked with this information. The anchor is illustrated in Figure 1.

A multicentre study was conducted to evaluate the position of the visualised anchor in relation to the uterine serosa

\section{Dirk Wildemeersch, ${ }^{*} \mathrm{MD}, \mathrm{PhD}$}

Director, Gynaecological Outpatient Clinic and IUD Training Centre, Ghent, Belgium;

d.wildemeersch@skynet.be

\section{Ansgar Pett, MD}

Director, Gynaecological Outpatient Clinic, Berlin, Germany; drpett@snafu.de

\section{Sohela Jandi, MD}

Co-Director, Gynaecological Outpatient Clinic, Uetze, Germany; dr.jandi@pett-jandi.de

\section{Kilian Nolte, MD}

Director, Gynaecological Outpatient Clinic, Feldkirchen, Austria; kilian@drnolte.com

*Corresponding author.

Competing interests Dr Wildemeersch is the developer of the GyneFix IUD. He acts as a trainer in GyneFix insertion for companies distributing the product. He has 
also been involved in the development and optimisation of new drug delivery systems for use in the uterus and he is currently an advisor on the development of new delivery methods for contraception and gynaecological treatment. He receives financial compensation for these activities.

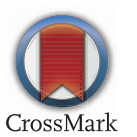

J Fam Plann Reprod Health Care 2014;40:310-311. doi:10.1136/jprhc-2014-100954

\section{REFERENCE}

1 Wildemeersch D, Pett A, Jandi S, et al. Precision intrauterine contraception may significantly increase continuation of use: a review of long-term clinical experience with frameless copper-releasing intrauterine contraception devices. Int J Womens Health 2013;5:215-225. 